Article

\title{
Interpersonal Antecedents to Selective Disclosure of Lesbian and Gay Identities at Work
}

\author{
Julian M. Rengers ${ }^{1,2, *}$, Liesbet Heyse ${ }^{1}$, Rafael P. M. Wittek ${ }^{1}$ and Sabine Otten ${ }^{2}$ \\ ${ }^{1}$ Department of Sociology, University of Groningen, The Netherlands; E-Mails: j.m.rengers@rug.nl (J.M.R.), \\ I.heyse@rug.nl (L.H.), r.p.m.wittek@rug.nl (R.P.M.W.) \\ 2 Department of Psychology, University of Groningen, The Netherlands; E-Mail: s.otten@rug.nl (S.O.) \\ * Corresponding author
}

Submitted: 10 June 2021 | Accepted: 1 October 2021 | Published: 15 December 2021

\begin{abstract}
Lesbian, gay, and bisexual (LGB) employees' sexual identity may be considered a concealable stigmatised identity. Disclosing it to others at work could potentially lead to discrimination and rejection, hence threatening their inclusion. Therefore, they may hide their sexual identity instead, which may then come at the cost of, e.g., guilt for not living authentically. However, disclosure is a continuum-rather than a dichotomy-meaning that LGB workers may decide to disclose selectively, i.e., telling some, but not all co-workers. Most literature on disclosure focuses on the interplay between intrapersonal (e.g., psychological) and contextual (e.g., organisational) characteristics, thereby somewhat overlooking the role of interpersonal (e.g., relational) characteristics. In this article, we present findings from semi-structured, in-depth interviews with nine Dutch lesbian and gay employees, conducted in early 2020, to gain a better understanding of interpersonal antecedents to disclosure decisions at work. Through our thematic analysis, we find that LGB workers may adopt a proactive or reactive approach to disclosure, which relates to the salience of their sexual identity at work (high/low) and their concern for anticipated acceptance. Other themes facilitating disclosure include an affective dimension, being in a relationship, and associating with the employee resource group. We demonstrate the importance of studying disclosure at the interpersonal level and reflect on how our findings relate to literature on disclosure, authenticity, belonging, and social inclusion of LGB individuals at work.
\end{abstract}

\section{Keywords}

authenticity; belonging; disclosure; identity management; inclusion; LGB employees; social relationships; thematic analysis

\section{Issue}

This article is part of the issue "In Good Company? Personal Relationships, Network Embeddedness, and Social Inclusion" edited by Miranda J. Lubbers (Autonomous University of Barcelona, Spain).

(C) 2021 by the authors; licensee Cogitatio (Lisbon, Portugal). This article is licensed under a Creative Commons Attribution 4.0 International License (CC BY).

\section{Introduction}

Lesbian, gay, and bisexual (LGB) employees, whose sexual identity can be considered a concealable stigmatised identity (Jones \& King, 2014), run an increased risk of being discriminated against, harassed, or socially excluded at work compared to their heterosexual co-workers (Webster et al., 2018). They therefore carefully manage their sexual identity in social interaction with others (Newheiser \& Barreto, 2014). Disclosing their sexual identity may potentially generate both costs (e.g., experience discrimination) and benefits (e.g., live authentically; Clair et al., 2005), as does concealing (e.g., feeling guilt for not being true to oneself vs protecting oneself against stigmatisation; Pachankis, 2007). Disclosure decisions, or choices about (non-)disclosure in particular situations (Ragins, 2008), therefore play a central role in the lives of LGB workers (Ragins et al., 2007). 
Two particular characteristics of disclosure decisions make it unlikely that LGB employees are completely uniformly "in" or "out" of "the closet" (Ragins, 2008). First, disclosure decisions reappear with each new social interaction or context (e.g., King et al., 2017); they constitute a continuous, lifelong process (Legate \& Ryan, 2014). Second, disclosure decisions are situated on a continuum, ranging from full concealment to full disclosure (Berkley et al., 2019). Along this continuum, LGB employees have a range of behavioural strategies at their disposal (e.g., "fabrication," "signalling," "normalising"; see Clair et al., 2005); they may selectively disclose their sexual identity and may differ concerning how "out" they are to different people at work (Legate et al., 2012). In fact, a majority of LGB employees likely engages in selective disclosure. In a survey by the European Union Fundamental Rights Agency (2020), 37\% of about 60,000 employed participants had disclosed to no one at work, $26 \%$ to a few, $16 \%$ to most-but not all-and $21 \%$ to all co-workers. Even if selective disclosure is common in practice (see also Griffith \& Hebl, 2002), perhaps more so than full concealment or full disclosure, it is often not studied in detail empirically.

This study addresses this gap by providing a more detailed understanding of LGB employees' selective disclosure decisions at work. We ask: How do interpersonal characteristics play a role in LGB employees' selective sexual identity disclosure decisions across social relationships with different colleagues? We argue that it is necessary to go beyond prevailing explanations predominantly focusing on the interplay between intrapersonal and contextual characteristics. Instead, we adopt an interpersonal approach, by studying lesbian and gay employees' dyadic social relationships at work, within which disclosure decisions occur (see Compton, 2016).

\section{Theoretical Background}

Existing literature predominantly focuses on intrapersonal and contextual antecedents to disclosure decisions. Among individual-level variables, the effects of the degree of self-acceptance, disclosure goals, identity centrality, identity confusion, internalised heterosexism, job satisfaction, personality variables, and private outness on disclosure decisions at work have been noted; contextual variables that have been studied concerning disclosure decisions at work include perceived heterosexist discrimination, LGBT supportive practices, organisational supportiveness, and workplace climate (e.g., Chaudoir \& Fisher, 2010; Fletcher \& Everly, 2021; Griffith \& Hebl, 2002; Ragins \& Cornwell, 2001; Reed \& Leuty, 2016; Wax et al., 2018). Disclosure decisions are guided by two potentially opposing fundamental psychological needs (Clair et al., 2005; Jones \& King, 2014). Individuals are motivated to find a balance between the differentiation of themselves from others, thereby fulfilling their need for uniqueness, while simultaneously feeling sufficiently embedded within a social group to satisfy their need for belonging (following Brewer, 1991). As fulfilment of the needs for belonging and authenticity-the expression of one's "true self," as a more broadly applicable concept than uniqueness-also determines individuals' perceived inclusion in social contexts (Jansen et al., 2014), LGB employees' disclosure decisions are closely related to their perceived social inclusion at work. Taken together, it is clear that disclosure decisions result from a highly complex process (Chaudoir \& Fisher, 2010).

In our study, we slightly shift focus compared to most literature, by approaching disclosure decisions at a within-person level (Jones \& King, 2014). This approach aims to understand how the same person may manage their identity differently in accordance with situational characteristics of a specific setting (e.g., King et al., 2017), for example across different social relationships with co-workers. A within-person approach is necessary to understand why an LGB employee may fully disclose to one colleague, whilst avoiding the topic altogether with another (Legate et al., 2012)-i.e., selective disclosure.

We argue that two factors particularly affect an individual employee's disclosure decision towards a specific other. First, the perceived level of "anticipated acceptance" (Jones \& King, 2014): the extent to which an LGB employee believes that an interaction partner would be accepting of their concealable stigmatised identity, should they disclose it. People with a high level of anticipated acceptance are more likely to elicit disclosure, and people with a low level of anticipated acceptance are less likely (for preliminary evidence see King et al., 2017). Previous research suggested several interpersonal characteristics that may increase anticipated acceptance, and thus disclosure likelihood: others who are perceived as having knowledge, being sympathetic, or being similar (e.g., possess the same stigmatised identity; Clair et al., 2005); relationships characterised by high degrees of (emotional) closeness and interpersonal trust (Derlega et al., 1993); others being a sexual minority, a woman, or lower in the hierarchical structure (King et al., 2017).

The second factor concerns the assessment of how disclosure might affect costs and benefits in terms of belonging and authenticity. The need for belonging consists of the motivation to create and maintain stable and strong social relationships; this can be fulfilled by having positive and recurring interactions with others in a group (Baumeister \& Leary, 1995). If LGB employees have positive, recurring interactions with colleagues, they may feel that they belong. In such cases, they may safely disclose, which helps resolve their need for authenticity. This could also occur in reverse: The need for authenticity consists of the motivation to stay true to oneself (Kernis \& Goldman, 2006), which can be fulfilled by feeling allowed and encouraged to be oneself within a social environment. If LGB employees experience this in a relationship with co-workers (for example because they constantly talk about their love for RuPaul's Drag Race), this may facilitate disclosure. Doing so may ease building a (strong) relationship, thereby satisfying the 
need for belonging. Finally, these processes may also negatively influence one another: LGB employees who have mostly negative or ambiguous interactions with co-workers may feel dissatisfaction regarding their need for belonging. This may hamper disclosure, which may endanger satisfying one's need for authenticity. Similarly, if one does not feel allowed and encouraged to be oneself, disclosure becomes less likely, which may create relational strain, since one may have to put up a facade (e.g., Pachankis, 2007). Concealment, however, can create a downward spiral and further decrease feelings of belonging and acceptance (Newheiser et al., 2017), partially because individuals will feel less authentic during social interactions (Newheiser \& Barreto, 2014). Taken together, anticipated costs and benefits regarding the fulfilment of the needs for belonging and authenticity within a social relationship may inform the choice of relational disclosure strategy, which may lead to selective disclosure at work.

In conclusion, characteristics of interaction partners-as well as characteristics of their relationships with LGB employees-have not been extensively studied in disclosure and identity management literature (King et al., 2017). Therefore, to address the relative dearth of such an interpersonal focus, we study the social relationships that LGB employees have with their co-workers in depth. Within and across these relationships, we investigate which factors affect (selective) disclosure decisions, and how exactly they may do so.

\section{Methods}

\subsection{Study Context and Participants}

This research was conducted at a large logistics company in the Netherlands, a country generally seen as relatively LGBT-friendly. It ranks relatively highly (12th out of 49 countries) on the annual Rainbow Index of the European branch of the International Lesbian, Gay, Bisexual, Trans, and Intersex Association (2021), which delineates the legal and policy position of LGBTI people across European countries. Moreover, 92\% of the population think homosexuality should be accepted by society (Pew Research Center, 2020). The company has been actively working towards creating an inclusive workplace. For example, they annually administer a diversity index measuring how well they are doing, and they invite external parties to evaluate their diversity and inclusion policies. Their diversity programmes received awards and the organisation is generally considered an inclusive employer. Especially interesting is that the company has one main office, as well as several warehouses, distribution centres, and depots across the country. This may make it challenging to ensure an equal commitment to, and implementation of, the centrally established diversity and inclusion policies across all layers and locations. Nonetheless, in an internal survey, $89 \%$ of LGBT-identified workers indicated that they feel accepted at work (R. Takken, personal communication, October 22, 2018).

Nine employees participated, seven of whom identified as male and gay, and two as female and lesbian; no one in our sample identified as bisexual. At the time of interviewing, two participants were married, four were in a committed, monogamous relationship, and three were single. All participants were native Dutch, had completed (at least) a bachelor's degree at university level, and their ages ranged from mid-20s to mid-50s. Most participants were full-time stationed in the company's main office, while some also worked in other locations. One participant worked in delivery. Other jobs held by participants were in IT or sales and ranged from project management to product development. Table 1 provides an overview of participants' relationship status, organisational tenure, disclosure antecedents, and their inductively created grouping.

Participants were recruited through the gatekeeper strategy paired with snowball sampling (see Hennink et al., 2011). We established contact with the company's employee resource group (ERG), which sent out a recruitment call via their mailing list and Facebook page. After participation, interviewees were also asked to forward the research details to other potentially interested colleagues.

\subsection{Data Collection Procedure and Data Analysis}

As part of a larger data collection, semi-structured in-depth interviews were conducted. The main advantages of this were (a) the possibility to establish rapport between researcher and interviewee, to discuss the potentially sensitive topic of sexual identity, and (b) ensuring that key questions were asked, while simultaneously allowing interviewees to bring up topics themselves (Hennink et al., 2011). The first author served as the interviewer in this research. All interviews were conducted face-to-face between January and March 2020. Opening questions addressed participants' demographics, work career, job content, and contact with colleagues. Key questions related to their sexual identity management, in general and at work, and in specific social relationships at work. To collect social network data, we adopted the hierarchical mapping technique (Antonucci, 1986), whereby people were prompted by the word "colleague" and invited to write down names, in descending order of closeness. The aim was to establish differences in disclosure behaviours vis-à-vis specific co-workers, to generate insights into interviewees' selective disclosure patterns. Finally, participants were asked about general work experiences-being a lesbian or gay employee working at this companyand how they thought their employer was doing in terms of diversity and inclusion. Interviews were audiorecorded following participant consent and verbatim transcripts were made, which were anonymised and pseudonymised afterwards. The study protocol was 
approved by the Ethics Committee of Sociology of the University of Groningen.

Data were analysed following thematic analysis (Braun \& Clarke, 2006). This analytic method provides a systematic approach to identify, analyse, and report patterns-or themes-across the data. Thematic analysis is an ongoing iterative process, which requires constantly moving between data and analysis; the first author familiarised himself with the data during interviewing, transcription, and multiple (re)readings of the transcripts. During this stage, he took notes to denote interesting aspects of the data. Herein he adopted an experiential lens, prioritising meanings that participants attach to their lived experiences. This approach fits within a critical realist framework, wherein individuals' meaning-making of their experiences is acknowledged, and that these processes are embedded in a broader social context (e.g., Willig, 1999). A combined deductive (i.e., theory-driven) and inductive (i.e., data-driven) approach was followed in identifying and developing codes and themes. Although data were analysed following specific theoretical ideas (e.g., focusing on interpersonal aspects of disclosure decisions), the data content could simultaneously inform and develop our analysis (e.g., the distinction between proactive and reactive disclosure). This approach led to several data-driven codes, based on which the first author identified patterns that could be developed into themes, particularly within the realm of disclosure. Thick descriptions of each case were made, and after in-depth discussion with one of the co-authors to further refine the themes, we conducted cross-case comparison, comparing a single code ("disclosure"; Hennink et al., 2011). This process led to our inductive grouping (see Table 1), which prompted a comparison by inductive subgroups, to explore differences within each group. Both interview guide and codebook are available in the Supplementary Materials.

\section{Findings}

We present four main findings: First, one participant's story demonstrates how different antecedents may be pivotal at different stages of the disclosure process. Second, participants preferred either a more proactive or reactive approach to disclosure. Third, we relate these approaches to participants' needs for authenticity and

Table 1. Participant details, groupings, and disclosure antecedents.

\begin{tabular}{|c|c|c|c|c|c|c|}
\hline \multirow[b]{2}{*}{$\begin{array}{l}\text { Name } \\
\text { (pseudonym) }\end{array}$} & \multirow[b]{2}{*}{$\begin{array}{l}\text { Relationship } \\
\text { status }\end{array}$} & \multirow[b]{2}{*}{$\begin{array}{l}\text { Tenure at } \\
\text { company }\end{array}$} & \multirow[b]{2}{*}{ Grouping } & \multicolumn{3}{|c|}{ Disclosure antecedents } \\
\hline & & & & Intrapersonal & Interpersonal & Contextual \\
\hline Arnold (M) & $\begin{array}{l}\text { Committed } \\
\text { relationship }\end{array}$ & $>15$ years & $\begin{array}{l}\text { Achieving authenticity; } \\
\text { proactive disclosure }\end{array}$ & $\begin{array}{l}\text { High sexual } \\
\text { identity } \\
\text { salience }\end{array}$ & $\mathrm{n} / \mathrm{a}$ & $\begin{array}{l}\text { Supportive } \\
\text { environment }\end{array}$ \\
\hline Willem (M) & Married & $>10$ years & $\begin{array}{l}\text { Achieving authenticity; } \\
\text { proactive disclosure }\end{array}$ & $\begin{array}{l}\text { High sexual } \\
\text { identity } \\
\text { salience }\end{array}$ & $\mathrm{n} / \mathrm{a}$ & $\begin{array}{l}\text { Supportive } \\
\text { environment* }\end{array}$ \\
\hline Corné (M) & Single & $>5$ years & $\begin{array}{l}\text { Achieving authenticity; } \\
\text { reactive disclosure }\end{array}$ & $\begin{array}{l}\text { Low sexual } \\
\text { identity } \\
\text { salience }\end{array}$ & $\begin{array}{l}\text { Contact, } \\
\text { closeness }\end{array}$ & No barriers \\
\hline Iza (F) & $\begin{array}{l}\text { Committed } \\
\text { relationship }\end{array}$ & 2 years & $\begin{array}{l}\text { Achieving authenticity; } \\
\text { reactive disclosure }\end{array}$ & $\begin{array}{l}\text { Low sexual } \\
\text { identity } \\
\text { salience }\end{array}$ & $\begin{array}{l}\text { Expected } \\
\text { future } \\
\text { relationship }\end{array}$ & $\begin{array}{l}\text { Supportive } \\
\text { environment* }\end{array}$ \\
\hline Leo (M) & $\begin{array}{l}\text { Committed } \\
\text { relationship }\end{array}$ & $>20$ years & $\begin{array}{l}\text { Achieving authenticity; } \\
\text { reactive disclosure }\end{array}$ & $\begin{array}{l}\text { Low sexual } \\
\text { identity } \\
\text { salience }\end{array}$ & $\mathrm{n} / \mathrm{a}$ & No barriers* \\
\hline Boudewijn (M) & Single & $2 \frac{1}{2}$ years & $\begin{array}{l}\text { Striving for belonging; } \\
\text { conditional disclosure }\end{array}$ & $\begin{array}{l}\text { Conditionally } \\
\text { open }\end{array}$ & $\begin{array}{l}\text { Scanning } \\
\text { for social norms }\end{array}$ & $\begin{array}{l}\text { Supportive } \\
\text { environment }\end{array}$ \\
\hline Madelief (F) & Married & $4 \frac{1}{2}$ years & $\begin{array}{l}\text { Striving for belonging; } \\
\text { conditional disclosure }\end{array}$ & $\begin{array}{l}\text { Conditionally } \\
\text { open }\end{array}$ & $\begin{array}{l}\text { Scanning } \\
\text { for comfort }\end{array}$ & $\begin{array}{l}\text { Supportive } \\
\text { environment }\end{array}$ \\
\hline Stijn (M) & Single & $>10$ years & $\begin{array}{l}\text { Striving for belonging; } \\
\text { conditional disclosure }\end{array}$ & $\begin{array}{l}\text { Conditionally } \\
\text { open }\end{array}$ & $\begin{array}{l}\text { Scanning } \\
\text { for acceptance }\end{array}$ & $\begin{array}{l}\text { Supportive } \\
\text { environment }\end{array}$ \\
\hline Tijmen (M) & $\begin{array}{l}\text { Committed } \\
\text { relationship }\end{array}$ & $>20$ years & $\mathrm{n} / \mathrm{a}$ & $\begin{array}{l}\text { Struggled to } \\
\text { find self- } \\
\text { acceptance }\end{array}$ & Trust is key & $\begin{array}{l}\text { Familiar } \\
\text { environment* }\end{array}$ \\
\hline
\end{tabular}

Notes: $\mathrm{F}=$ female, $\mathrm{M}$ = male; * = engagement in activities for ERG facilitated disclosure "by association" (see Section 4.5). 
belonging and find that their sexual identity salience at work, as well as scanning for anticipated acceptance, play a key role in these processes. Fourth, we highlight several crosscutting themes that further exemplified other elements related to disclosure.

\subsection{A Processual View of Disclosure: The Exemplary Story of Tijmen}

Eight out of nine participants were largely "out" in their personal lives when they started working for this organisation. One participant, however, went through this process of self-acceptance while he worked here. His story powerfully demonstrates the processual nature of disclosure and illustrates how various antecedents on intrapersonal, interpersonal, and contextual levels can be more or less prevalent across different stages of this process.

Tijmen was in a committed long-term relationship with a woman-although he did have sex with men since long before that. He did not call himself gay, because he did not dress or behave like the gays he saw on TV. Hence, he kept this identity hidden for a long time. At some point, she found out, however; they broke up and he struggled to find self-acceptance as a gay person. When he first joined the company, he had not yet accepted his sexual identity privately and found it therefore difficult to disclose to others. At some point, he disclosed within his tight-knit team of four people, but only after he trusted them sufficiently. One of them later outed him to a new colleague, which he did not appreciate because he did not sufficiently trust that person yet. Indeed, at that time, he "considered trust, as if I am sharing a secret" to be the key ingredient to disclosure. After relocating to another department, where he became manager, he generally did not disclose, which was motivated by (a) seeing his sexuality as a secret, (b) the hierarchical distance between him and his colleagues, and (c) his team members gossiping about his sexual identity. He only disclosed to one person, then: a woman with whom he felt a close emotional connection-whom he therefore trusted. He moved back to his former department and, strengthened by two pivotal moments in his life-these being (a) having a committed relationship with a man and (b) participating in the company's ERG - he felt confident enough to start living openly as a gay man. Since then, he has been very open about his sexual identity at work, and he now "find[s] it difficult to behave differently than how [he] feels." In principle, he now does not give it much thought, which is illustrated by his appearance in an interview with the ERG in the company newsletter, effectively telling everyone: "I am gay; share it with the whole country, I am fine with it!"

\subsection{Disclosure as Proactive or Reactive}

A key finding, and an essential distinction to make in studying selective disclosure, is the approach participants took to discussing their personal life-including their sexual identity-at work, which can be either more proactive or reactive. Some participants $(n=2)$ preferred a proactive form of disclosure, bringing up these topics of their own volition, rather than waiting for others to ask. They voiced a strong need for authenticity and saw not being fully authentic as an unbearable cost that they were unwilling to carry; it was simply not an option for them to compromise who they are. Most participants ( $n=6$ ) however, preferred a reactive approach; they would not be likely to bring up their personal life themselves but preferred waiting to be asked about it. They did this for several different reasons, on which we elaborate in the following sections.

\subsection{Achieving Authenticity, Yet in Different Ways}

Following our theoretical framework, we propose that several participants' experiences can be seen in light of their need for authenticity, paired with varying degrees of sexual identity salience at work. Identity salience generally refers to the relative importance of a certain identity within a given social context (following selfcategorisation theory, e.g., Turner et al., 1987). Whereas Arnold and Willem found their sexual identity highly salient at work, Corné, Iza, and Leo indicated low workplace sexual identity salience.

\subsubsection{High Sexual Identity Salience and Proactive Disclosure: Arnold and Willem}

Two participants expressed the salience of their sexual identity and their need to be authentically themselves as gay men. This high sexual identity salience shone through in their preference for proactive disclosure, as they neither scanned for anticipated acceptance nor made their disclosure dependent on interpersonal factors.

Before Arnold started working here, he worked at several other companies where he did not disclose because these had a more masculine, classical organisational culture. Moreover, since no one else was openly gay, he did not feel the need to disclose. After joining this organisation, he entered a department where he recognised many co-workers from gay bars, so he found it easy to disclose instantaneously. After having transferred to another location, he was a bit more cautious, but he found that the company offered a safe environment, and therefore he felt free to tell others. This co-occurred with him joining a gay association, where he gained a lot of confidence, up to the point that he no longer cares about what others think (of him being gay). He does not want to adapt to others and he will no longer make concessions because this is who he is- "and if others have a problem with that, it is their problem." He holds authenticity as the greatest good, which translates into a preference for a proactive approach to disclosure: He chose to "very actively, at new jobs, new job interviews... mention it from day one. It is also on [his] CV," as well as on his LinkedIn and Facebook pages. 
When Willem first joined the company, he had not yet met his current husband-this happened a month later. In the beginning, he was looking for a natural way to disclose to others, which was greatly facilitated by being in a relationship, as well as by his involvement with the company's ERG. Nowadays, he tends to explicitly say he is "married to [his] husband Dirk" when he meets new colleagues, "because they may otherwise have wrong expectations." This means that, much like Arnold, he has adopted a proactive approach to disclosure. He considers it a subtle way to correct people's (heteronormative) assumptions and to make homosexuality visible. His predisposition to disclose proactively is predominantly motivated by "find[ing] it, in the end, nice for others to know who [he is], what keeps [him] warm, and what [he does]." Moreover, being authentically himself helps establish a genuine connection with others, something Willem finds very important.

\subsubsection{Low Sexual Identity Salience and Reactive Disclosure: Corné, Iza, and Leo}

Three participants emphasised that their sexual identity was not relevant to them at work. They would reactively disclose if asked but did not feel a need to disclose proactively to be authentically themselves. They would like to be viewed as "more" than their sexual identity and aim to achieve their authenticity in other ways. All three indicated that they would talk openly about their personal life outside of work, for example during drinks, which would be further facilitated by working together a lot with someone and knowing them personally.

Corné started working at this company when he was already comfortably out in his personal life. After a rather difficult process towards self-acceptance, he nowadays does not consider it an issue anymore, especially not at work: Even if he never felt a barrier to disclose, it is simply irrelevant there, he reckons. He would not be likely to just bring it up out of the blue to everyone he meets, and he would not introduce himself by saying " 'hi, I am Corné, I am gay,' because that has nothing to do with [the] job." He also points out that, e.g., during workrelated meetings, where everyone is simply there to discuss topics $x, y$, and $z$, and not their personal life, it is not necessary to disclose. Indeed, he also does not know of those colleagues e.g., "where they live, whether they are married, whether they are LGBTQI," and does not need them to know this about him either. Nonetheless, with the colleagues with whom he works together a lot, has a lot of contact with, or knows a bit better, hence has a somewhat more personal-as opposed to a businesslike relationship-he tends to be very open about his sexual identity.

When Leo first joined the organisation, he was still figuring out for himself whether he was maybe into both men and women. Therefore, in the beginning, he was not very open about his sexual identity-although he did disclose it during his job interview. After relocating after sev- eral years, with both himself and society having developed in that time, he started being more open about being in a committed relationship with a man. He does so by simply talking about, e.g., what they did during the weekend when prompted by his colleagues about that, and he has never experienced any barrier that prevented him from talking about his boyfriend. However, he considers work to be work in the first place, and he simply finds his sexuality an irrelevant part of his identity there: "The first thing at work is not ' I am Leo and my boyfriend is called Marco.' The first thing is 'I am Leo, and this is my job, and let's get started." Outside of work, e.g., in a bar, if someone were to ask him about his personal life he would answer truthfully, and he would be happy to talk more in-depth, but he does not see the need to discuss it at work.

When Iza first started working at the organisation, she joined a team of six. At a certain point, during lunch, as they started to get to know one another, she was very open about her sexual identity-and nowadays, "basically everyone" at work knows. However, "when you first enter, and everything is still new, you are obviously asked 'do you have a boyfriend'? It is a very common question." Her gut reaction is often to respond "no," thus technically telling the truth. This response tends to be more common when she only expects to see them for five minutes. However, sometimes she will say: "No, but I do have a girlfriend." Such a response is more common when she expects to be working a lot together in the future; in such cases, she will elaborate. Either way, she ascertained that "if you were to ask about it, [she] would always answer truthfully." She would be unlikely to bring up her sexual identity at her own volition, however, because she does not want to be seen for just her sexuality and the label that she may then have. Instead, she wants to be judged based on how she is around others, and for how she is as a person. This also makes her somewhat hesitant to talk freely about her personal life-not only her sexual identity-around others who are higher up in the hierarchy, as she is afraid they might get a "bad" impression of her.

\subsection{Striving for Belonging Through Anticipated Acceptance and Conditional Disclosure: Boudewijn, Madelief, and Stijn}

The remaining three participants talked about how they make some of their disclosure decisions conditional on cues by others that indicate anticipated acceptance. What they considered important cues, however, differed between them. They gauged either the prevalent work culture and social norms (Boudewijn) or their interaction partner (Madelief, Stijn) for cues that indicated whether they would feel comfortable disclosing their sexual identity in this situation. In line with our theoretical framework, their hesitation could be seen as a perceived necessity to safeguard their belonging: They are uncertain of whether disclosing could potentially harm 
their relationship with others, and therefore first evaluate whether others would be accepting.

Boudewijn entered the company after having had to lower his workload due to mental health issues. He realised that the more open he is-whether this concerns his sexual identity or his mental health issuesthe more recognition others will have. Hence, generally speaking, he is very open about what is happening in his life. However, he would not bring it up himself; there has to be a cause for it, for example when someone asks him about his personal life. This happened in one of the depots where he works: Someone asked whether he has a girlfriend, and "it is a very normal thing to say" for him, so he "never doubted about making that into a big deal." Since others also talked openly about their personal lives and issues, he felt free to do the same. However, in another depot, they only asked why he was working there, so he told them about his mental health issues. His sexual identity, on the other hand, was never a topic of inquiry. Since he noticed in conversation with others that they also did not talk about their personal life themselves, he did not see the need to say anything about it either: It is simply something these colleagues do not know of one another. Hence, Boudewijn scanned his environment carefully to gauge the prevalent social norm within the different contexts and adjusted his behaviour to the particular setting in which he was working.

When Madelief started working at the organisation, she immediately told her team of five men about her sexual identity-possibly on the first day even; she recalls now that "it does not feel like it was a thing." She then moved to her current location, where she again immediately told her co-workers-maybe not consciously, but when they asked her, she would tell them. However, she does notice a difference here: With her co-workers with whom she shares an office, she is very open. They work together every day and there is a very informal atmosphere. In the warehouse adjacent to her office building, however, which she regularly visits for work, she finds it much more difficult to tell others. She did not mention it to everyone there because she did not necessarily feel comfortable doing so, as she felt a bit more distant from them. Additionally, since colleagues there tend to have a lower education level, or be of different cultural backgrounds, she feared that they might be less open towards homosexuality, or know less about it-hence, she feared that they might potentially view her sexual identity as problematic. Even if these are somewhat stereotypical assumptions based on the other's group membership, her initial trepidation felt more justified when she heard comments like "you are probably married [to a man]" or "at your age, you have to be married [to a man]." Such comments made her think: "Never mind, at least I will not tell them myself." She thinks that if someone in the warehouse were to ask her whether she has a boyfriend, she would say "'no, but I do have a wife.' But [I would] not [tell them] of my own accord."
Stijn had only been out privately for a year when he joined the organisation, so he had only just started his journey of self-acceptance. In addition, since he was new, and employed on a temporary contract, he did not disclose for the first two years. He was afraid that other people may think of him negatively and feared that coming out as gay may taint his image, so he pretended to have a girlfriend. However, living that lie did eat away at him, and he was actively looking for a natural moment to disclose. When a colleague somewhat pressured him into giving the name of his "girlfriend," he took that as an opportunity to have his first coming out at worksomething he now regrets not having done earlier. After having moved to a different location, he had to disclose again; this was facilitated by the birth of his son, which prompted him to bring beschuit met muisjes (a Dutch treat that parents of new borns hand out to celebrate the birth of their baby) to work. When colleagues asked him how his wife was doing, it was another perfect, natural moment for him to say that this is not his wife: He effectively disclosed to all his colleagues-nowadays everyone knows he is gay. He now prefers disclosing as early as possible (but not too early), to not give people the wrong impression, since "otherwise there will be a discrepancy between who people think you are and the real you... and the longer you wait, the more difficult it becomes." However, sometimes disclosure "is not worth the investment"; to gauge such situations, he scans his interaction partners for signals that may convey acceptance, measuring whether disclosing would somehow harm others' perceptions of him. He found this especially valuable while working in international settings, since "you don't know how people think about gays." He reckons that when conversations get more personal, if others possess a certain degree of openness, and if he feels a connection with them, he feels comfortable to disclose.

\subsection{Crosscutting Themes: Relationship Status as a} Facilitator to Disclosure, the Importance of an Affective Dimension, and Disclosure by Association

Besides the findings presented above, we noticed several crosscutting themes. First, several participants $(n=4)$ found that being in a relationship-rather than being single-makes it easier to disclose one's sexual identity. For example, Willem reckons that disclosing is trickier when you do not have a partner:

[If] you are not in a relationship... what do you have to say about it then?...When you do have a partner, it is easy: 'I have a boyfriend.' But when you do not, you have to say 'but I am into men,' which I find a bit weird.

Iza echoes this sentiment; for example, when introducing herself, she would say: "I am Iza and I live in..." Then, if she expects to have a long-term working relationship with them, she would add: "I live together with [followed by a female name]." The same applies to being married, 
she argues: During an introduction, one would naturally say "my husband," or "my wife." Simultaneously, if she were single, she would not say "I am into women" while introducing herself, "as there is no particular reason to do so then." Finally, Boudewijn first disclosed-at a previous employer-once he was in a committed relationship with a man because he "found that a good moment to tell others-just as anyone else would."

Second, several participants $(n=4)$ referred to the importance of an affective dimension, related to feelings and emotions, that facilitates disclosure. Examples of facilitating factors - which have also been found in other research (Derlega et al., 1993; Webster et al., 2018)included perceived (emotional) closeness, interpersonal trust, and mutually sharing details about one's personal life. For example, Corné mentioned: "With the group of colleagues with whom I'm closer... you tend to talk about 'what did you do on the weekend'... or 'how is your relationship going'... that's fine." Similarly, Boudewijn found that with "colleagues who are also open themselves, [he] automatically [has] a natural connection...[he has] more to talk about." Finally, Madelief's story demonstrated how having a better relationship with others facilitates disclosure: When she first met her new Muslim colleague, she "found it trickier to tell him immediately." She first needed to determine what his opinion on the topic was and asked herself: "Can I be myself or not?" After she got to know him better, she disclosed to him: "I do really have a lot of contact with him, and I just know he is a sweet man... so at some point, we got to talking about it, and then it is good."

Third, participants $(n=4)$ talked about how, by engaging with the company's ERG, they implicitly had their coming out. Such "disclosure by association," where one does not actively voice one's sexual identity, but rather leaves it up to others to deduce it from associating with the ERG, occurred in several distinct ways. Willem, for example, through his work with Pride Amsterdam, confirmed his manager's suspicions that he was gay. Tijmen gave an interview for the company newsletter on behalf of the ERG, thereby effectively making his membership of the LGBTQ+ community public. Leo's face is still on a Pride poster that was made several years ago and which is reused now and again, such that others may recognise him as a member of the community. Finally, Iza recalled a story of some colleagues seeing her on the company boat during Pride Amsterdam, which prompted them to ask why she was there. Such "disclosure by association" may have, to a certain extent, replaced their explicit coming out, as well as generally lowered the threshold to disclose to colleagues.

\section{Discussion}

\subsection{Contributions and Implications}

In this study, we set out to identify how interpersonal characteristics play a role in selective disclosure of an
LGB identity at work, thereby answering a call for more empirical research on understanding disclosure from a within-person perspective (King et al., 2017). We proposed that disclosure decisions to a specific other effectively result from two processes, namely the degree of anticipated acceptance and a cost-benefit assessment of one's need for belonging and authenticity. Our main contributions to disclosure literature are twofold. First, the distinction between a proactive and a reactive approach to disclosure has, to the best of our knowledge, not been reported previously. This finding further illuminates the linkages between disclosure and the needs for belonging and authenticity (see also Fletcher \& Everly, 2021; Newheiser et al., 2017), and, hence, to LGB employees' perceived inclusion (following Jansen et al., 2014). For some, the need for authenticity as an LGB person is so central-and their sexual identity so salient-that they disclose proactively, regardless of interpersonal (e.g., relational) characteristics, thereby leaving little room for selective disclosure. They do not gauge for anticipated acceptance and would possibly accept lower satisfaction of their belonging need, since being an authentically LGB person is key to them.

A reactive approach to disclosure was more common, however, albeit for different reasons. Several participants voiced a low identity salience at work, effectively rendering their sexual identity irrelevant in that domain. They preferred achieving authenticity by focusing on other aspects of their identity. This translated to them not bringing up their sexual identity of their own volition; they preferred waiting to be asked about it, upon which they would disclose. This reactive approach was also preferred by other participants who were somewhat concerned that their disclosure may potentially not be met with acceptance and therefore showed a tendency to scan their environment first. During this process, we found that different people might pay attention to different kinds of cues, thereby contributing to our understanding of anticipated acceptance (Jones \& King, 2014). LGB employees may choose to do so to be in control of determining who-and who not-to tell about their sexual identity. Reactive disclosure, which could be called "conditional" in this case, can then be an instrument to further deepen already existing relationships or to safely establish new ones. In a sense, these workers accept a temporarily lower satisfaction of their need for authenticity to make sure that, once they disclose, this will not hurt their belonging need.

Second, we primarily set out to study interpersonal antecedents to disclosure decisions. We do indeed find indications that this level may be relevant for LGB workers, given how an affective dimension facilitates disclosure for some participants, as well as how others scan their social environment for cues indicating anticipated acceptance. As such, our study resonates with previous qualitative work showing how disclosure studied from an interpersonal perspective is a dynamic, multifaceted process (e.g., Galvin-White \& O'Neal, 2016). Our study 
especially highlights, however, the intricate manner in which intrapersonal, interpersonal, and contextual characteristics interplay throughout different stages of the sexual identity disclosure process at work (cf. Tijmen's story). As such, this study proposes that (a) an interpersonal approach adds valuable information to the study of disclosure decisions at work and (b) that the interpersonal level should feature more explicitly-in conjunction with the intrapersonal and contextual levels - in future research.

\subsection{Limitations and Opportunities for Future Research}

Several limitations should be noted. First, we recruited LGB workers in one particular organisation, which is known as an inclusive employer, situated in the Netherlands, which is a relatively LGBT-friendly country. Second, the social contexts wherein our participants worked were relatively homogeneous: most worked in the main office, with relatively little variation in co-workers' educational level. Several participants alluded to the different reality, e.g., in warehouses, where working with co-workers from a range of cultural or religious backgrounds may make disclosure an entirely different process (Madelief's story). Third, all participants were generally very open about their sexual identity, which made studying selective disclosure somewhat more difficult and limited the added value of the social network mappings to our study. Those who generally prefer to conceal may, for example, pay more attention to interpersonal antecedents. A final limitation that should be mentioned is the small sample size of our study, which means we have to be cautious in interpreting the claims that we are putting forth in this article. Nevertheless, even within this small, relatively homogeneous sample, several participants described hesitations concerning disclosure, partly concerning interpersonal factors.

These limitations also open up opportunities for future research. Our study could be extended to other organisations in other countries. Especially when organisational climates are less optimal for disclosure, interpersonal antecedents driving disclosure are likely more salient; in such cases, and among LGB workers who are less uniformly open about their sexual identity, copying our hierarchical mapping technique may uncover exciting new intricacies around selective disclosure. Future studies could also delve deeper into what contributes to "anticipated acceptance." Correspondingly, our study calls for large-scale empirical substantiation of the identified themes, and their relation to potentially relevant (intrapersonal) characteristics. Herein one can think of concepts such as identity salience, centrality, valence, and authenticity concerns. Another potentially interesting avenue is to sample bisexual workers, who may have different considerations about selective disclosure, especially when they are in a same-sex relationship. Finally, disclosure literature would be vastly enriched if we also include a focus on disclosure recipients. Interesting research questions here relate to, e.g., how active or passive their role is in this process.

\section{Conclusion}

Our study further elucidates how disclosure of LGB workers' sexual identity is a dynamic, context-dependent, multi-dimensional process, affected by interpersonal antecedents-as well as intrapersonal and contextual factors. Even if work environments are safe and supportive, and even if LGB workers are generally open about their sexual identity, interpersonal processes may still play a role in disclosure decisions. Altogether, we highlight that managing a concealable stigmatised identity is an ongoing process. Accordingly, there is still a long way to go towards equality and justice for LGBTQIA* people. Continuing to study their lived experiences and lift their voices is a necessary step to achieve that.

\section{Acknowledgments}

The authors would like to thank their contact person at the company's ERG for establishing contact with the participants, as well as Gonneke Ton for providing an invaluable sounding board. This study is funded by the PhD Scholarship programme at the Faculty of Behavioural and Social Sciences, University of Groningen, the Netherlands, and is part of the research programme Sustainable Cooperation-Roadmaps to Resilient Societies (SCOOP). The contributions of L. H. and R. P. M. W. are (partially) funded by the Netherlands Organization for Scientific Research (NWO) and the Dutch Ministry of Education, Culture and Science (OCW) in the context of its 2017 Gravitation programme (grant number 024.003.025).

\section{Conflict of Interests}

The authors declare no conflict of interest.

\section{Supplementary Material}

Supplementary material for this article is available online in the format provided by the authors (unedited).

\section{References}

Antonucci, T. C. (1986). Measuring social support networks: Hierarchical mapping technique. Generations: Journal of the American Society on Aging, 10(4), 10-12.

Baumeister, R. F., \& Leary, M. R. (1995). The need to belong: Desire for interpersonal attachments as a fundamental human motivation. Psychological Bulletin, 117(3), 497-529. https://doi.org/10.1037/ 0033-2909.117.3.497

Berkley, R. A., Beard, R., \& Daus, C. S. (2019). The emo- 
tional context of disclosing a concealable stigmatized identity: A conceptual model. Human Resource Management Review, 29(3), 428-445.

Braun, V., \& Clarke, V. (2006). Using thematic analysis in psychology. Qualitative Research in Psychology, 3(2), 77-101.

Brewer, M. B. (1991). The social self: On being the same and different at the same time. Personality and Social Psychology, 17(5), 475-482.

Chaudoir, S. R., \& Fisher, J. D. (2010). The disclosure processes model: Understanding disclosure decisionmaking and post-disclosure outcomes among people living with a concealable stigmatized identity. Psychological Bulletin, 136(2), 236-256.

Clair, J. A., Beatty, J. E., \& MacLean, T. L. (2005). Out of sight, but not out of mind: Managing invisible social identities in the workplace. The Academy of Management Review, 30(1), 78-95. https://doi.org/10.5465/ AMR.2005.15281431

Compton, C. A. (2016). Managing mixed messages: Sexual identity management in a changing US workplace. Management Communication Quarterly, 30(4), 415-440.

Derlega, V. J., Metts, S., Petronio, S., \& Margulis, S. T. (1993). Self-disclosure. SAGE.

European Union Fundamental Rights Agency. (2020). A long way to go for LGBTI equality. https://fra. europa.eu/sites/default/files/fra_uploads/fra-2020Igbti-equality-1_en.pdf

Fletcher, L., \& Everly, B. A. (2021). Perceived lesbian, gay, bisexual, and transgender (LGBT) supportive practices and the life satisfaction of LGBT employees: The roles of disclosure, authenticity at work, and identity centrality. Journal of Occupational and Organizational Psychology, 94(3), 485-508. https://doi.org/ 10.1111/joop.12336

Galvin-White, C. M., \& O'Neal, E. N. (2016). Lesbian police officers' interpersonal working relationships and sexuality disclosure: A qualitative study. Feminist Criminology, 11(3), 253-284. https://doi.org/ 10.1177/1557085115588359

Griffith, K. H., \& Hebl, M. R. (2002). The disclosure dilemma for gay men and lesbians: "Coming out" at work. Journal of Applied Psychology, 87(6), 1191-1199. https://doi.org/10.1037/0021-9010.87. 6.1191

Hennink, M., Hutter, I., \& Bailey, A. (2011). Qualitative research methods. SAGE.

International Lesbian, Gay, Bisexual, Trans, and Intersex Association. (2021). Rainbow Europe map. https:// www.ilga-europe.org/sites/default/files/ Attachments/Rainbow\%20Europe\%20Map\% 202021_0.pdf

Jansen, W. S., Otten, S., Van der Zee, K. I., \& Jans, L. (2014). Inclusion: Conceptualization and measurement. European Journal of Social Psychology, 44(4), 370-385. https://doi.org/10.1002/ejsp.2011

Jones, K. P., \& King, E. B. (2014). Managing concealable stigmas at work: A review and multilevel model. Journal of Management, 40(5), 1466-1494. https://doi. org/10.1177/0149206313515518

Kernis, M. H., \& Goldman, B. M. (2006). A multicomponent conceptualization of authenticity: Theory and research. In M. P. Zanna (Ed.), Advances in experimental social psychology (pp. 283-357). Elsevier Academic Press.

King, E. B., Mohr, J. J., Peddie, C. I., Jones, K. P., \& Kendra, M. (2017). Predictors of identity management: An exploratory experience-sampling study of lesbian, gay, and bisexual workers. Journal of Management, 43(2), 476-502. https://doi.org/10.1177/ 0149206314539350

Legate, N., Ryan, R. M., \& Weinstein, N. (2012). Is coming out always a "good thing"? Exploring the relations of autonomy support, outness, and wellness for lesbian, gay, and bisexual individuals. Social Psychological and Personality Science, 3(2), 145-152. https:// doi.org/10.1177/1948550611411929

Legate, N., \& Ryan, W. S. (2014). Autonomy support as acceptance for disclosing and developing a healthy lesbian, gay, bisexual or transgendered identity. In N. Weinstein (Ed.), Human motivation and interpersonal relationships. Theory, research, and applications (pp. 191-212). Springer.

Newheiser, A.-K., \& Barreto, M. (2014). Hidden costs of hiding stigma: Ironic interpersonal consequences of concealing a stigmatized identity in social interactions. Journal of Experimental Psychology, 52, 58-70. https://doi.org/10.1016/j.jesp.2014.01.002

Newheiser, A.-K., Barreto, M., \& Tiemersma, J. (2017). People like me don't belong here: Identity concealment is associated with negative workplace experiences. Journal of Social Issues, 73(2), 341-358. https://doi.org/10.1111/josi.12220

Pachankis, J. (2007). The psychological implications of concealing a stigma: A cognitive-affective-behavioral model. Psychological Bulletin, 133(2), 328-345. https://doi.org/10.1037/0033-2909.133.2.328

Pew Research Center. (2020). The global divide on homosexuality persists. https://www.pewresearch. org/global/2020/06/25/global-divide-onhomosexuality-persists

Ragins, B. R. (2008). Disclosure disconnects: Antecedents and consequences of disclosing invisible stigmas across life domains. The Academy of Management Review, 33(1), 194-215. https://doi.org/10.2307/ 20159383

Ragins, B. R., \& Cornwell, J. M. (2001). Pink triangles: Antecedents and consequences of perceived workplace discrimination against gay and lesbian employees. Journal of Applied Psychology, 86(6), 1244-1261. https://doi.org/10.1037//0021-9010.86.6.1244

Ragins, B. R., Singh, R., \& Cornwell, J. M. (2007). Making the invisible visible: Fear and disclosure of sexual orientation at work. Journal of Applied Psychology, 92(4), 1103-1118. https://doi.org/10.1037/ 
0021-9010.92.4.1103

Reed, L., \& Leuty, M. E. (2016). The role of individual differences and situational variables in the use of workplace sexual identity management strategies. Journal of Homosexuality, 63(7), 985-1017. https://doi.org/ 10.1080/00918369.2015.1117900

Turner, J. C., Hogg, M. A., Oakes, P. J., Reicher, S. D., \& Wetherell, M. S. (1987). Rediscovering the social group: A self-categorization theory. Blackwell.

Wax, A., Coletti, K. K., \& Ogaz, J. W. (2018). The benefit of full disclosure: A meta-analysis of the impli- cations of coming out at work. Organizational Psychology Review, 8(1), 3-30. https://doi.org/10.1177/ 2041386617734582

Webster, J. R., Adams, G. A., Maranto, C. L., Sawyer, K., \& Thoroughgood, C. (2018). Workplace contextual supports for LGBT employees: A review, metaanalysis, and agenda for future research. Human Resource Management, 57(1), 193-210. https://doi. org/10.1002/hrm.21873

Willig, C. (1999). Applied discourse analysis: Social and psychological interventions. Open University Press.

\section{About the Authors}

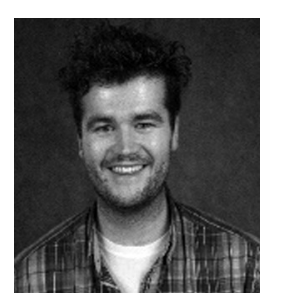

Julian M. Rengers (MScRes 2017, University of Groningen, the Netherlands) is a PhD candidate at the Departments of Sociology and Psychology at the University of Groningen. In his project, he studies under which conditions people with a concealable stigmatised identity disclose their identity to others at work, with a specific focus on LGB workers. Moreover, he studies how this relates to their perceived workplace inclusion.

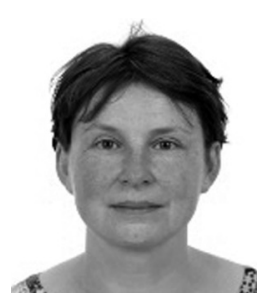

Liesbet Heyse (PhD 2002, Leiden University, the Netherlands) is associate professor of Sociology at the University of Groningen. She studies how public, non-profit, and private organisations address societal challenges through their operations, studying their governance structures, organisational practices, and performance. She applies these questions-in close collaboration with stakeholders-to specific settings, such as Dutch municipalities and NGOs working on the labour market integration of refugees and in the youth care sector, using both quantitative and qualitative methods.

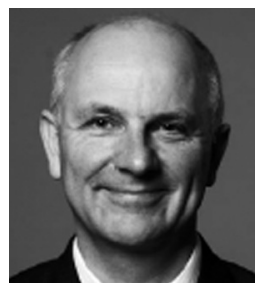

Rafael P. M. Wittek (PhD 1999, University of Groningen, the Netherlands) is professor of theoretical sociology at the Department of Sociology at the University of Groningen. Moreover, he is the scientific director of the interdisciplinary research and training centre Sustainable Cooperation-Roadmaps to Resilient Societies (SCOOP). His research focuses on problems of sustainable cooperation and how to prevent and solve them. His areas of expertise are the sociology of organisations, economic sociology, social network analysis, and social theory.

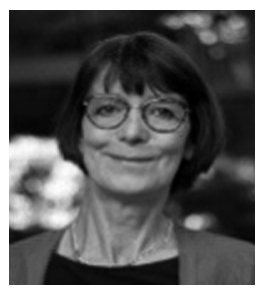

Sabine Otten (PhD 1991, University of Münster, Germany) is professor of intergroup relations and social integration at the Psychology Department of the Faculty of Behavioural and Social Sciences of the University of Groningen in the Netherlands. In recent years, her research has mostly focused on identifying the characteristics, determinants, and outcomes of psychological inclusion in diverse groups, thereby specifically focusing on cultural diversity. 